\title{
Unemployment and the Speed of Transition in China*
}

Shuo Huang

Southwestern University of Finance and Economics

Liulin Campus (Main Campus): 555, Liutai Avenue, Wenjiang District, Chengdu, Sichuan, 611130, P. R. China

shuang@swufe.edu.cn or huangshuo0926@gmail.com

Jan Fidrmuc (corresponding author)

Department of Economics and Finance, and Centre for Economic Development and Institutions (CEDI)

Brunel University

Uxbridge, UB8 3PH, UK.

Jan.Fidrmuc@brunel.ac.uk or jan@fidrmuc.net.

Phone: +44-1895-266-528.

http://www.fidrmuc.net/

Institute of Economic Studies, Charles University, Opletalova 26, 11000 Prague, Czech Republic

CESIfo Munich, Poschingerstr. 5, 81679 München, Germany

JEL Codes: E24, E61, J64.

Keywords: Unemployment; Okun's Law; Growth; Optimal Speed of Transition;

China.

\footnotetext{
* We benefited from comments and suggestions received at presentations at Brunel University, Bank of Finland, and Southwestern University of Finance and Economics in Chengdu, as well as from Iikka Korhonen, Jarko Fidrmuc, and Wing Thye Woo. This research was in part carried out while Jan Fidrmuc and Shuo Huang were visiting the Bank of Finland Institute for Economies in Transition (BOFIT), whose hospitality and financial support are gratefully acknowledged.
} 


\section{Abstract}

We investigate the relationship between unemployment and growth in China. We find considerable differences in the nature of this relationship across Chinese regions. We argue that this may reflect the different progress in transition across regions, in line with the Aghion-Blanchard model of optimal speed of transition. When we test this model, we find strong evidence of a hump-shaped relationship between unemployment and our proxy for the speed of reform. The current unemployment in China, furthermore, appears to be close to the level associated with the optimal speed of transition. 


\section{Introduction}

Despite China's rapid economic growth since 1978, the last two decades have also brought about a steady increase in unemployment, which has become one of the most pressing problems facing the Chinese economy at present. Intuitively, we would expect that high output growth should help keep unemployment low. This would be in line with Okun's Law, one of the basic rules of macroeconomics, which postulates an inverse relationship between output growth and changes in unemployment (Okun 1962). However, Okun's Law was formulated in the context of a mature market economy, the United States. China, in contrast, has been undergoing a dramatic and multifaceted transition since 1978: from central planning to a market economy, and from a primarily agrarian and closed economy to an industrialized and open one.

The process of economic transition has had a major impact on China's urban labor market. As the other former communist countries, China started its transition with full employment. The pre-reform labor market was characterized by four key features. First, the bulk of the labor force was employed in agriculture. Second, urban workers enjoyed life- long employment without any fear of dismissal or unemployment. Third, the hukou 
system of household registration restricted the ability of workers to move between rural and urban areas and across regions. Fourth, welfare policies including the rationing of basic necessities, social security policy exclusive to urban regions and other public service provisions (the so-called 'iron rice bowl') further restricted labor mobility and equal treatment of residents in rural and urban areas (Cai and Wang 2010). The reform led to a liberalization of urban employment and broke the 'iron rice bowl'. As a result, the allocation of labor in urban regions has become mostly market-based, although the hukou system and differentiated provision of public goods and social security in urban and rural regions have remained in place and continue to impede labor mobility between rural and urban areas. The subsequent privatization of state-owned enterprises in the late 1990s, in turn, has given rise to unemployment in urban areas (Cai and Wang 2010). Around ten million workers were laid off from state owned enterprises and urban collectives in 1996 and in 1997 alone.

The experience of China has differed markedly from that of the post-communist countries in Eastern Europe. In the former, output grew steadily and at relatively high rates, while unemployment stayed, especially initially, modest. In the latter, the onset of transition was associated with a sudden and sharp contraction and a rapidly growing and persistently high unemployment, in a process labeled 'Transformational Recession' (Kornai 
1994). A number of studies have sought to shed light on the reasons behind these differences (see Roland, 2000, and Woo, 2014, for broad overviews). An important difference between China and Eastern Europe was in the speed and sequencing of reform. The Eastern European countries implemented multiple reforms at once and at a relatively high pace, in a big-bang fashion. China, in contrast, elected a more cautious approach: reforms were implemented gradually and in a dual-track fashion, the latter meaning that the centrally-planned sector was maintained but private initiatives were allowed at the margin. Another important difference was the high share of agriculture in the Chinese economy at the beginning of the reforms. This ensured a vast supply of potential labor for the manufacturing sector once the reform created favorable incentives for its expansion.

Aghion and Blanchard (1994) formulate a theoretical model of reform of centrally-planned economies in which they seek to explain some of the stylized facts of the post-communist transition, such as differences in the pace of reform and the associated economic outcomes across countries. They posit that there is an important relationship between unemployment and the speed of reform. Specifically, unemployment, which arises when workers in ailing state-owned enterprises lose their jobs, puts downward pressure on wages. This, in turn, helps facilitate the expansion of the 
private sector. At the same time, however, unemployment increases the tax burden imposed on the private sector, whose taxes are used to finance unemployment benefits. This results in an inverted U-shaped relationship between unemployment and the speed of reform. When unemployment is too low, private sector workers require excessively high wages, so that the private sector grows only slowly or not at all. Under high unemployment, taxes become too high, which again impedes the expansion of the private sector. The inverted U-shaped relationship implies that there is a single intermediate level of unemployment that is optimal in the sense that it maximizes the expansion of the private sector. The major insight of the Aghion-Blanchard model for China, therefore, is that growing unemployment need not undermine China's future prospects. In fact, while in several Eastern European countries unemployment may have exceeded the optimal level, the current unemployment in China remains relatively low and may well be lower than the optimal value. ${ }^{1}$

In this paper, we investigate empirically the nature of the relationship between unemployment and economic growth generally, and the speed of reform specifically, in China. There are only a few previous studies on this

1 The average official unemployment rate during the period covered by our analysis is 3.5 percent. The World Development Indicators report unemployment as increasing from 4.2 to 4.6 percent between 2010 and 2013. 
issue in the Chinese context, and these restrict their attention to the relationship between growth and unemployment at the aggregate level. To the best of our knowledge, no prior studies have addressed the relationship between unemployment and the speed of reform in China. Moreover, since the existing studies only consider the Chinese economy as a whole (Wu 2003; Cai and Wang 2010), they ignore the regional aspects of this relationship. The regional dimension is likely to be crucial in China because of the way reform was implemented: the coastal provinces in Eastern China were allowed to implement reforms first, with the rest of the country following gradually.

In the next section, we briefly discuss the literature on the relationship between unemployment and growth in mature market economies and in countries in transition from central planning. Section 3 presents the data used in our analysis. Section 4 estimates a standard Okun's relationship in China, while Section 5 approaches this relationship more generally, without being restricted by a particular theoretically motivated or empirically observed rule. Finally, Section 6 argues that the pattern observed in China can be explained in the context of the Aghion and Blanchard (1994) model on the relationship between unemployment and the speed of reform. Section 7 concludes. 


\section{The relationship between unemployment and growth}

In his original article, Okun (1962) suggests that, on average over the post-war period, each percentage point of the unemployment rate above four percent was associated with real GNP being lower by approximately three percent. Since Okun's seminal contribution, this has become accepted as one of the fundamental rules of macroeconomics. The aggregate supply curve, for example, is derived by combining Okun's relation with the Philips curve (Moosa 1997).

The negative sign of Okun's coefficient has been confirmed in the literature, although its magnitude is sensitive to model specification, choice of control variables, econometric methods and sample periods. Smith (1975), Gordon (1984), Weber (1995) and Prachowny (1993) confirm it with US data. Kaufman (1988), Lee (2000), and Moosa (1999) present international evidence and find significant differences among countries. Courtney (1991), Harris and Silverstone (2001) and Silvapulle et al. (2004), in turn, argue that Okun's coefficient may be different in periods of expansion and contraction.

While there are numerous studies on Okun's law in the context of developed countries, little attention has been given to whether this 
relationship holds in formerly centrally-planned economies. Izyumov and Vahaly (2002), one of the few exceptions, investigate Okun's relationship for 25 transition countries, which they divide according to their reform progress into leaders and laggards. They show that the standard Okun's relationship emerges in transition countries only after transformation has progressed sufficiently. Wu (2003), one of the few studies on China, found Okun's law to be non-linear in China over the period 1988-98.

Okun's Law is an empirically observed rather than theoretically derived relationship. As such, it stipulates correlation and says little as to whether the direction of causality goes from growth to unemployment or the other way around. Aghion and Howitt (1994), who build on Pissarides (1990), develop a model of the relationship between unemployment and growth, which suggests there are two types of effects: "capitalization" and "creative destruction". The capitalization effect reflects the fact that an increase in growth raises capitalized returns by decreasing the discount rate, which increases the present benefit of entry and hence increases the number of job openings. This, in turn, reduces the equilibrium rate of unemployment. This stands in contrast to the creative destruction effect, according to which an increase in growth may reduce the life time of production units and thus raises the equilibrium level of unemployment by raising the job separation rate. In order to take advantage of innovation, old machines need to be shut 
down by the firm. When this happens, workers become unemployed until matched with a new machine. Aghion and Howitt show that the "creative destruction' effect dominates at low growth rates while the 'capitalization' effect dominates at high ones, leading to a hump shaped relationship between unemployment and growth. The sign of the relationship between growth and unemployment can therefore be either positive or negative.

The Aghion and Blanchard (1994) model has been formulated to capture the specific circumstances prevailing in countries in transition from central planning to a market economy. They suggest that the speed of labor reallocation during transition and the rate of unemployment are connected in an inverted U-shaped fashion. Figure 1 depicts this relationship, with unemployment denoted as $U(t)$ and the growth of private-sector employment by $\dot{\mathrm{N}}_{p}(t)$. This shape stems from the fact that unemployment affects the private sector in two ways. First, wages of private-sector workers are inversely related to unemployment: high unemployment raises the value having a job and therefore the private sector can get away with paying lower wages. Second, unemployment benefits are financed by taxes on the private sector. Therefore, excessive unemployment depresses the after-tax profits of private firms. If there is no unemployment, the private sector cannot develop because it relies on the unemployment pool to recruit workers (and to depress their wage demands). In contrast, when 
unemployment reaches $1-b /(1-\rho c)$, the tax burden becomes too high and the private sector cannot exist either. Since the relationship between the speed of job destruction in the state sector (speed of reform) and unemployment is hump-shaped, there is an optimal level of unemployment, $U^{*}$, which maximizes $\dot{\mathrm{N}}_{p}(t)$, the speed of expansion of the private sector. Note that the inverted U-shaped relationship posited by Aghion and Blanchard also implies that the relationship between unemployment and growth (or speed of reform) can be either positive or negative.

\section{Data}

In our analysis, we use data for Chinese administrative regions: these include 22 provinces, 5 autonomous ethnic-minority regions (Tibet, Xinjiang, Guangxi, Ningxia and Inner Mongolia) and 4 metropolitan regions (Beijing, Shanghai, Tianjin and Chongqing). For simplicity, we refer to all of them as provinces in the remainder of the paper. Although there are 31 provinces, we exclude Chongqing and Tibet due to insufficient data. We divide the provinces into three broad regions: East, Center and West: this division is motivated not only by geography but also by the spread of reforms throughout China. The provinces belonging to each group are shown in Table 1. The period considered is 1997-2006: the market mechanism should be more prominent in the determination of 
employment and output during this period (Izyumov, and Vahaly 2002) and unemployment was limited before this period.

Output is measured as real provincial GDP and has been obtained from the Chinese National Statistical Bureau. Unemployment is the registered urban unemployment rate as reported in the China labor statistical yearbook. Measuring unemployment poses a particular difficulty in China. Rural residents tend to be underemployed rather than unemployed because they can fall back on farm work when other paid work is not available (Giles et al. 2005). Furthermore, neither hidden unemployment nor the so-called xia gang (usually translated as 'laid-off') workers are counted as unemployed (Jackman 1998; Clarke and Borisov 1999). Xia gang workers are those who are temporarily unemployed but nevertheless continue to maintain formal employment relations with their enterprise. Often, although they receive no pay, they receive in-kind benefits such as living in company-owned housing and/or having their national insurance paid by their employers (Gu 1999). Therefore, they are not officially reported as being unemployed.

There are a number of alternative estimates calculated based on published government data on employment, registered unemployment, and numbers of xia gang workers. However, Giles et al. (2005) point out that such 
estimates based on administrative data are subject to potentially serious shortcomings and none of them are calculated in a way that is consistent with standard international practice. They construct "true" unemployment rates calculated based on the 2002 follow-up survey to the China Urban Labor Survey, which complies with international practice for defining unemployment. Their estimates include the xia gang among the unemployed, as long as they meet the standard international criteria for being categorized as unemployed. The correlation between the official urban registered unemployment rate and their true unemployment rate is high: 0.98 . Therefore, the difference in the definition of the unemployment rate should not substantially affect the direction of the findings of our study. Since their estimates are limited in their coverage, in this paper we use the official urban registered unemployment as a proxy for the "true" unemployment rates.

Finally, we measure the speed of transition as the change in the number of private employees, which includes workers in firms belonging to individuals, share holders, joint ventures with stakes held by foreigners, foreign funds, investors from Hong Kong, Taiwan or Macao, share cooperatives, and limited liability companies. 


\section{Is there a relationship between unemployment and growth in China?}

There are two conventional specifications for estimating Okun's relationship: the "first- difference" and "gap" models. The first-difference model uses real GDP (or GNP) growth and the first difference of unemployment, as given by the following expression:

$$
\Delta U=a-b(\Delta Y / Y)
$$

The gap model, instead, considers the difference between the observed and natural rate of unemployment, and the difference between the observed and potential GDP, or output gap:

$$
U-\bar{U}=a+b(Y-\bar{Y})
$$

where $\bar{U}$ and $\bar{Y}$ stand for the natural rate of unemployment and the potential GDP, respectively.

For China, there are no reliable estimates of potential GDP, NAIRU, or similar macroeconomic benchmarks. Therefore, only the first-difference model is feasible for our study. We follow Izyumov and Vahaly (2002) and estimate the following relationship:

$$
y_{i, t}-y_{i, t-1}=\alpha+\beta\left(u_{i, t}-u_{i, t-1}\right)+\varepsilon_{i, t}
$$

where $i$ denotes provinces, $t$ represents years, $y_{i, t}$ is the log of real output (GDP), $u_{i, t}$ is the unemployment rate, $\alpha$ is the intercept reflecting the average real GDP growth rate, $\beta$ is Okun's coefficient, and $\varepsilon_{i, t}$ is the 
disturbance term. Okun's law suggests that the growth rate of output should be negatively related to the first difference of the unemployment rate: $\beta<0$. We estimate this relationship with Least Square Dummy Variable (LSDV) approach, both at the national level (including all Chinese provinces) and for the three broad regions discussed above: East, Center and West. The results are reported in Table 2. Okun's coefficient for all of China is negative but insignificant for the full period, 1997-2006. When we consider sub-periods, the coefficient is positive but insignificant for the first half (1997-2001), but negative and strongly significant during the later period, 2002-06. As expected, Okun's law holds only after the market-oriented reforms have progressed sufficiently. The results for East and Center are similar to each other: there is a negative and significant relationship between changes in unemployment and growth during the full period, in line with the pattern observed for developed countries. When considering sub-periods, the coefficients are negative but insignificant for 1997-2001. For 2002-06, the coefficients are negative and significant, which implies that an Okun's type of relationship is present. The West region, however, is strikingly different from the East and the Center. During the full period, 1997-2006, the estimated relationship is positive and highly significant. Neither of the results for the sub-periods is significant: it is positive during the early sub-period and negative (and almost significant at the 5 percent level) during the late sub-period. 
These results are in line with the findings of Izyumov and Vahaly (2002), which examine post- communist transition countries and find that Okun's Law holds only in those countries that have made enough progress in market-oriented reform. The pattern observed in the West sub-sample, however, goes against Okun's law: during the full period, 1997-2006, the relationship between the GDP growth rate and changes of unemployment rate is in fact positive and significant while it is not significant in either of the sub-periods. These differences in the nature of the relationship between growth and unemployment may be driven by the uneven progress in implementing economic reform in China. The East region was exposed to reform measures and the market economy much earlier than the Center and especially the West. That would explain also why Okun's relation can be found in the East and Center during the later sub-period for but not during the earlier one and in neither sub-period for the West. We address this issue in the following two sections.

\section{The relationship between growth and unemployment}

Much of the previous empirical literature on this topic is concerned with the effect of growth on unemployment. However, there are also likely to be forces running in the opposite direction. High unemployment may have an 
adverse effect on growth in the presence of a learning-by-doing effect, reducing the pool of savings available for investment in physical or human capital or knowledge-creating activities (Bean and Pissarides 1993). We therefore investigate both possibilities: the impact of growth on unemployment and that of unemployment on growth. We consider both linear and non-linear regression specifications and find the explanatory power of the latter to be greater. Therefore, we adopt a non-linear LSDV specification.

Table 3 shows how growth affects unemployment. It is clear that there is a hump-shaped relationship between unemployment and growth in the full sample, as well as in the East, Center and West sub-samples. These results confirm the prediction of Aghion and Howitt (1994) that the sign of the effect of growth on unemployment can be either positive or negative. Specifically, high rates of growth are negatively correlated with unemployment while low rates of growth are positively correlated with unemployment. The turning points (peak points), that is the rates of growth at which the effect changes from positive to negative, are 22 percent, 13 percent, 19 percent and 15 percent for the full sample, and East, Center and West sub-samples, respectively. Given that most provincial growth rates (see Figure 2) are below these turning points, unemployment may in fact increase further if Chinese growth goes up. In other words, in the context of 
the Aghion and Howitt (1994) model, the creative destruction effect dominates in China at present.

Table 4, in turn, considers the effect of unemployment on growth. The results are more mixed and less clear-cut than those above. There is again a hump-shaped relationship between unemployment and growth in the full sample, and in the West and East sub-samples. However, the relationship estimated for the Center sub-sample is neither significant for 1997-2006 nor for 1997-2001. The turning points, that is, values of unemployment associated with peak growth for the full data set and the East and West sub-sets are 5.28 percent, 2.53 percent and 4.9 percent, respectively. In East China, unemployment should always lower growth as most of the observed unemployment levels are greater than the turning point of 2.53 percent (Figure 3). Hence, further increases in unemployment may inhibit economic growth in this region. In West China, unemployment is mainly lower than the turning point of 4.9 percent, which implies that a positive relationship between unemployment and growth should prevail in that region.

Crucially, although the aforementioned results suggest the presence of a relationship between unemployment and growth, it is merely indicative of correlation between them, not of the direction of causality going one way or another. In such a situation, one can either attempt to resolve this question 
by using instrumental variables or take guidance from theory. The former is notoriously difficult, especially when it comes to finding suitable instruments. As for the latter, we believe the Aghion-Blanchard model (1994) on the relationship between unemployment and the speed of reform is particularly instructive.

\section{Trade-off between speed of reform and unemployment}

The major insight of the Aghion-Blanchard model is that there is an intermediate optimal level of unemployment whereas too much or too little of it can hurt the economic prospects of a country in transition. Given that China started its transition with essentially no unemployment, increasing unemployment should therefore be associated with a faster expansion of the private sector, at least initially. Assuming that the private sector is the main driving force behind economic growth, this relationship would also explain the pattern identified in the preceding section: the effect of unemployment on growth being negative in East China, where reforms have progressed relatively far, insignificant in Central China, and positive in the West.

Since the model stipulates a hump-shaped relationship between the speed of reform and unemployment, we regress the change in the number of private employees, our proxy for the speed of reform, on a quadratic polynomial of 
the unemployment rate. The results based on the full sample, reported in Table 5, strongly support the model: there is an inverted U-shaped relationship between the speed of transition and unemployment rate in China and this relationship is significant at the 1 percent level. Hence, at low levels, increasing unemployment should increase the speed of transition whereas the opposite should be the case in regions with already high unemployment. The optimal speed of transition is predicted to be attained at an unemployment rate of 3.53 percent. In fact, China's average unemployment rate was 3.54 percent over the period covered in this analysis. $^{2}$ Hence, the relatively moderate unemployment prevailing in China at present should not be seen as a necessarily negative phenomenon. Rather, it may be necessary to help facilitate China's transition and economic reform. Short-term hardship thus will be outweighed by long-term economic gain (Valev 2004).

\section{Conclusions}

2 This appears very low, compared to developed economies as well as other transition economies as we use the registered unemployment rate. This should be interpreted as a proxy for the actual true unemployment rate, which is certainly higher. However, as we mentioned earlier, the use of registered unemployment rate as a proxy should not affect the sign and the direction of our results. 
The above analysis sheds some light on the economic implications of growing unemployment in China. We find that the negative relationship between growth and unemployment, the well-known Okun's Law, is only emerging in China. Specifically, we find evidence that such a negative relationship prevails in Central and Eastern China, especially in more recent times, but not in Western China where the relationship may in fact be positive. This mirrors the fact that the reforms were initially limited only to Eastern China and thereafter spread inland gradually, from East to West. China has thus implemented its reform following a pattern of geographical gradualism.

So far, the unemployment level in China remains moderate: the latest figure, for 2013, reports the official unemployment rate as 4.6 percent. $^{3}$ The Aghion and Blanchard (1994) model suggests that an intermediate level of unemployment is necessary to achieve an optimal speed of transition. Our empirical estimates suggest that the current unemployment rate in China is indeed close to the optimal rate. Unemployment is thus one of the prices that China may need to pay for future prosperity.

\section{References}

3 World Development Indicators 2015. 
Aghion, Philippe, and Oliver J. Blanchard. 1994. On the Speed of Transition in Central Europe. In NBER Macroeconomics Annual, edited by Stanley Fischer, and Julio Rotemberg pp.283-319. Cambridge, Mass.: MIT Press.

Aghion, Philippe, and Peter W. Howitt. 1994. Growth and Unemployment. Review of Economic Studies 61: 477-94.

Bean, Charles, and Christopher Pissarides. 1993. Unemployment, Consumption and Growth. European Economic Review 37: 837-854.

Cai, Fang, and Meiyan Wang. 2010. Growth and structural changes in employment in China. Journal of Comparative Economics 38:71-81.

Clarke, Simon, and Vadim Borisov. 1999. New forms of labor contract and labor flexibility in Russia. Economics of Transition 7 (3): 593-614.

Courtney, Hugh George. 1991. The Beveridge Curve and Okun's Law: A Re-Examination of Fundamental Relationships in the United States. Ph.D. diss., Massachusetts Institute of Technology.

Giles, John, Albert Park and Juwei Zhang. 2005. What is China's true unemployment rate? China Economic Review 16:149-170.

Gordon, Robert J., and Peter K. Clark. 1984. Unemployment and Potential Output in the 1980s. Brooking Papers on Economic Activity 15(2): 537-564.

Gu, Edward X.1999. From permanent employment to massive lay-offs: The political economy of 'transitional unemployment' in urban China (1993-1998). Economy and Society 28 (2): 281-299. 
Harris, Richard, and Brain. Silverstone. 2001. Testing for Asymmetry in Okun's Law: Cross-Country Comparison. Economics Bulletin 5(2):1-13.

Izyumov, Alexei, and John Vahaly. 2002. "The unemployment-output tradeoff in transition economies: does Okun's law apply? Economics of Planning 35: 317-331. Jackman, Richard. 1998. Unemployment and Restructuring. In Emerging From Communism: Lessons from Russia, China and Eastern Europe. edited by Boone, P., S. Gomulka, and R. Layard (eds), Cambridge, MA, MIT Press and London, $123--152$.

Kaufman, Roger T. 1988. An International Comparison of Okun's Law. Journal of Comparative Economics 12: 182-202.

Kornai, János. 1994. Transformational Recession: The Main Causes. Journal of Comparative Economics 19: 39-63.

Lee, Jim. 2000. The Robustness of Okun's Law: Evidence from OECD Countries. Journal of Macroeconomics 22(2): 331-356.

Moosa, Imad A. 1997. A cross-country comparison of Okun's coefficient. Journal of Comparative Economics 24 (3): 335-356.

Moosa, Imad A. 1999. Cyclical Output, Cyclical Unemployment and Okun's Coefficient: Structural Time Series Approach. International Review of Economics and Finance 8: 293-304.

Okun, Arthur M. 1962. Potential GNP: Its Measurement and Significance. Proceedings of the Business and Economic Statistics Section, pp. 89-104. American Statistical Association. 
Pissarides, Christopher A. 1990. Equilibrium Unemployment Theory. Oxford: Blackwell.

Prachowny, Martin F. J. 1993. Okun's Law: Theoretical Foundations and Revised Estimates. Review of Economics and Statistics 75(2): 331-336.

Roland, Gérard. 2000. Transition and Economics, Politics, Markets, and Firms. Cambridge, Mass.: MIT Press.

Silvapulle, Paramsothy, Imad A. Moosa, and Mervyn Silvapulle. 2004. Asymmetry in Okun's Law. Canadian Journal of Economics 37(2): 353-374.

Smith, Gary. 1975. Okun's Law Revisited. Quarterly Review of Economics and Business 15: 37-54.

Valev, Neven. 2004. No pain, no gain: market reform, unemployment, and politics in Bulgaria. Journal of Comparative Economics 32: 409-425.

Weber, Christian E. 1995. Cyclical Output, Cyclical Unemployment and Okun's Coefficient: A New Approach. Journal of Applied Econometrics 10(4): 433-445. Woo, Wing Thye. 2014. Transition from Central Planning: Why Recession in Russia but Growth in China? University of California, Davis. Mimeo. Wu, Zhong M. 2003. Regional Unemployment in Transitional China: A Theoretical and Empirical Analysis. Economics of Planning 36: 297-314.

Table 1 Regional Sub-groups

\begin{tabular}{lc}
\hline Sample & \multicolumn{1}{c}{ Observations } \\
\hline East & Beijing, Tianjin, Shanghai, Liaoning, Shandong, Jiangsu, \\
\cline { 2 - 2 }
\end{tabular}


Zhejiang, Fujian, Guangdong, Hainan

Central Hebei, Shanxi, Neimenggu, Jilin, Heilongjiang, Anhui, Jiangxi,

Henan, Hunan, Hubei

West Guangxi, Guizhou, Yunnan, Sichuan, Shannxi, Gansu, Ningxia, Qinghai, Xinjiang

Source: based on National Bureau of Statistics of the People's Republic of China, The Fourth Session of the sixth National People's Congress. 
Table 2 Okun's coefficient, LSDV panel approach

\begin{tabular}{|c|c|c|c|}
\hline & Period & Okun's coefficient & t-Statistics \\
\hline \multirow{6}{*}{ China } & $1997-2006$ & -0.000924 & -0.519247 \\
\hline & & {$[0.001780]$} & \\
\hline & $1997-2001$ & 0.000212 & 0.367136 \\
\hline & & {$[0.000578]$} & \\
\hline & $2002-2006$ & $-0.015068 * * *$ & -5.237059 \\
\hline & & {$[0.002877]$} & \\
\hline \multirow{6}{*}{ East } & $1997-2006$ & $-0.013416 * * *$ & -3.630902 \\
\hline & & {$[0.003695]$} & \\
\hline & $1997-2001$ & -0.001656 & -0.490475 \\
\hline & & [0.003376] & \\
\hline & $2002-2006$ & $-0.009531 * * *$ & -3.399882 \\
\hline & & [0.002803] & \\
\hline \multirow{6}{*}{ Central } & $1997-2006$ & $-0.011868 * *$ & -2.166914 \\
\hline & & [0.005477] & \\
\hline & $1997-2001$ & -0.001420 & -0.474572 \\
\hline & & [0.002992] & \\
\hline & $2002-2006$ & $-0.034073 * * *$ & -4.472599 \\
\hline & & {$[0.007618]$} & \\
\hline \multirow{6}{*}{ West } & $1997-2006$ & $0.004012 * *$ & 2.021445 \\
\hline & & [0.001985] & \\
\hline & $1997-2001$ & 0.000343 & 0.551241 \\
\hline & & [0.000623] & \\
\hline & $2002-2006$ & -0.011758 & -1.924081 \\
\hline & & [0.006111] & \\
\hline
\end{tabular}

Source: Author's calculation, based on database of National Bureau of Statistics of the People's Republic of China.

Note: Standard errors in parentheses. ***1 percent significance, **5 percent significance. 
Table 3 Unemployment as function of growth during 1997-2006

\begin{tabular}{ccccc}
\hline Variables & Full sample & East & Central & West \\
\hline Constant & $1.703510 * * *$ & -2.561383 & $0.974850 * *$ & $2.297389 * * *$ \\
& {$[0.301767]$} & {$[2.143907]$} & {$[0.395113]$} & {$[0.206061]$} \\
$g^{2}$ & $-54.49003 * * *$ & $-371.2240 * * *$ & $-90.15515 * * *$ & $-78.43072 * * *$ \\
& {$[21.56805]$} & {$[161.2112]$} & {$[25.72050]$} & {$[23.78040]$} \\
$g$ & $23.75909 * * *$ & $95.36929 * *$ & $34.41178 * * *$ & $24.05964 * * *$ \\
& {$[5.166393]$} & {$[37.65610]$} & {$[6.549670]$} & {$[4.459429]$} \\
$R^{2}$ & 0.78 & 0.81 & 0.78 & 0.92 \\
\hline
\end{tabular}

Source: Author's calculation, based on database of National Bureau of Statistics of the People's Republic of China.

Note: $U$ is the unemployment rate. $g$ is the growth rate. Standard errors in parentheses.

$* * * 1$ percent significance, $* * 5$ percent significance.

Table 4 Growth as function of unemployment during 1997-2006

\begin{tabular}{ccccc}
\hline Variables & Full sample & East & Central & West \\
\hline Constant & $0.019748 * *$ & $0.067158 * * *$ & 0.050354 & $-0.045893 * * *$ \\
& {$[0.010074]$} & {$[0.015763]$} & {$[0.041436]$} & {$[0.011111]$} \\
$U^{2}$ & $-0.003442 * * *$ & $-0.005454 * * *$ & 0.001544 & $-0.006269 * * *$ \\
& {$[0.000570]$} & {$[0.001560]$} & {$[0.003659]$} & {$[0.000490]$} \\
$U$ & $0.036363 * * *$ & $0.027556 * * *$ & 0.009283 & $0.061769 * * *$ \\
& {$[0.004883]$} & {$[0.010182]$} & {$[0.024942]$} & {$[0.004794]$} \\
$R^{2}$ & 0.40 & 0.81 & 0.30 & 0.71 \\
\hline
\end{tabular}

Source: Author's calculation, based on database of National Bureau of Statistics of the People's Republic of China.

Note: $U$ is the unemployment rate. $g$ is the growth rate. Standard errors in parentheses.

$* * * 1$ percent significance, $* * 5$ percent significance. 
Table 5 Interaction between the speed of transition and unemployment during 1997-2006

\begin{tabular}{cc}
\hline Variables & Full sample \\
\hline Constant & $-287.1233^{* * *}$ \\
& {$[52.11857]$} \\
$U^{2}$ & $-24.97831^{* * *}$ \\
& {$[3.890164]$} \\
$U$ & $176.3222^{* * *}$ \\
$R^{2}$ & {$[28.81680]$} \\
\hline
\end{tabular}

Source: Author's calculation, based on database of National Bureau of Statistics of the People's Republic of China.

Note: $U$ is the unemployment rate. $g$ is the growth rate. Standard errors in parentheses.

***1 percent significance, **5 percent significance. 
Figure 1 The optimal level of unemployment $U^{*}$ and the maximal speed of transition $\dot{N}_{p}^{*}$

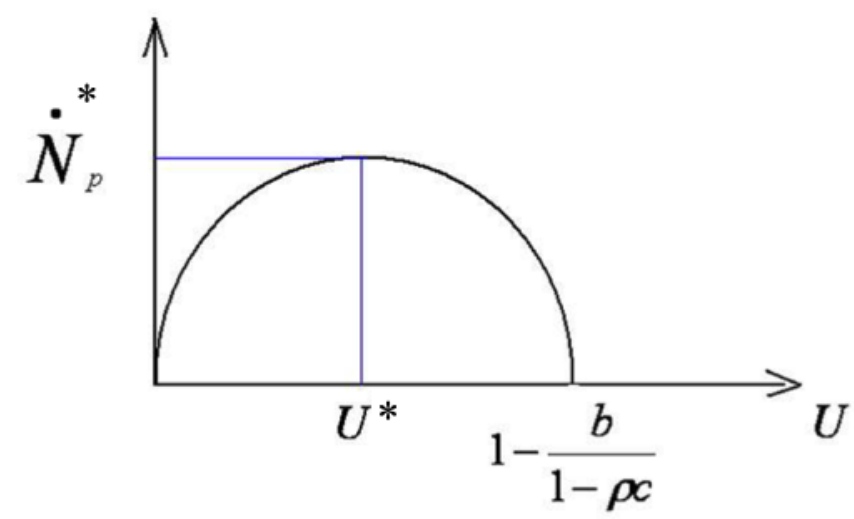

Source: Roland, Gérard. 2000. Transition and Economics, Politics, Markets, and Firms. Cambridge, Mass.: MIT Press. 
Figure 2 Growth rate: Chinese regions
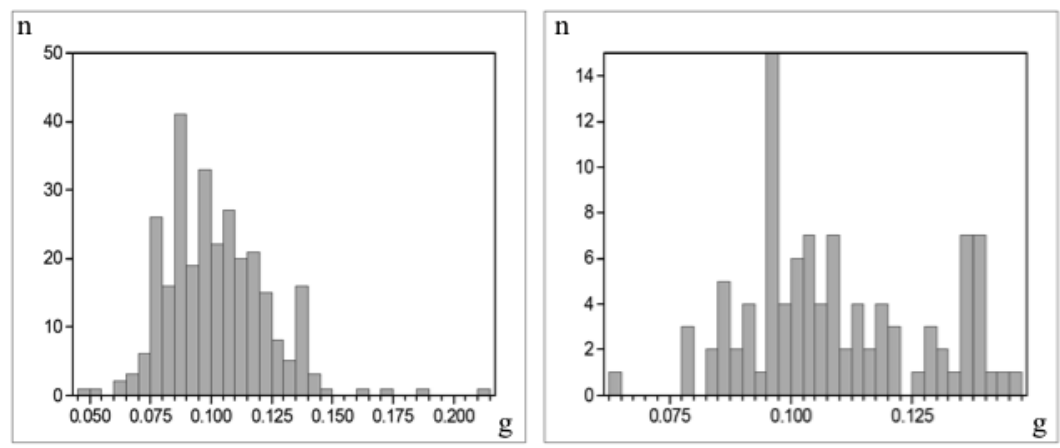

Growth-Full Sample Mean:0.102

Growth-East Sample Mean: 0.109
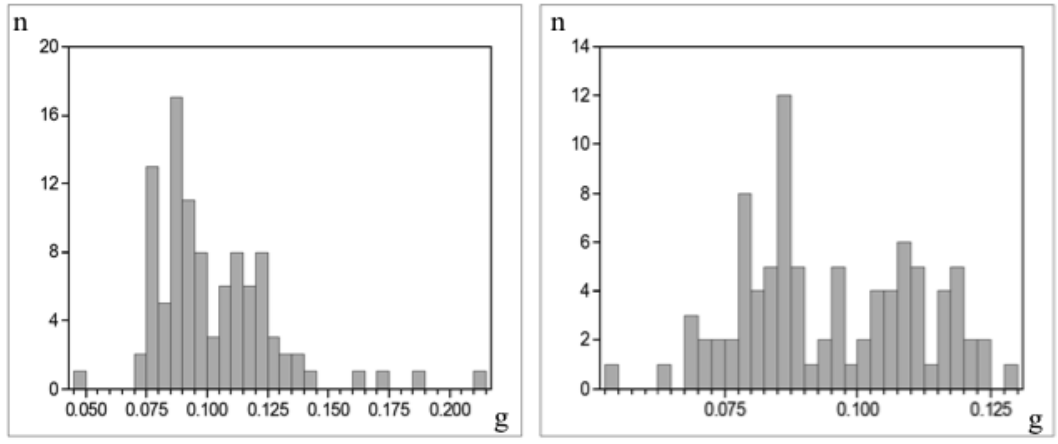

Growth-Central Sample Mean: 0.103

Growth-West Sample Mean: 0.095

Source: Author's calculation, based on database of National Bureau of Statistics of the People's Republic of China.

Note: $n$ is the number of observations; $g$ is the growth rate. 
Figure 3 Unemployment rate: Chinese regions

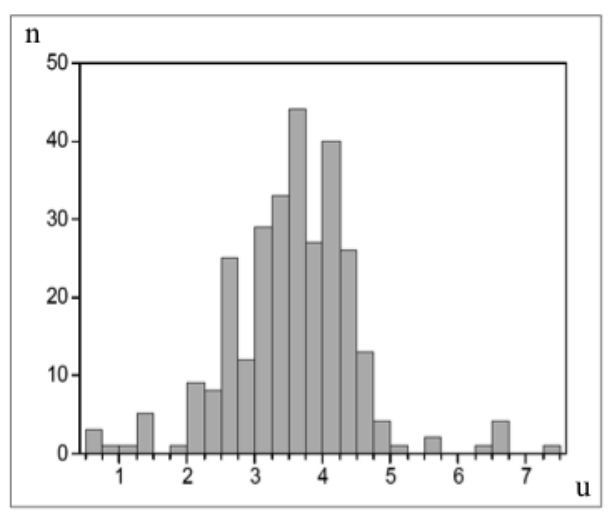

Unemployment-Full Sample Mean:3.54

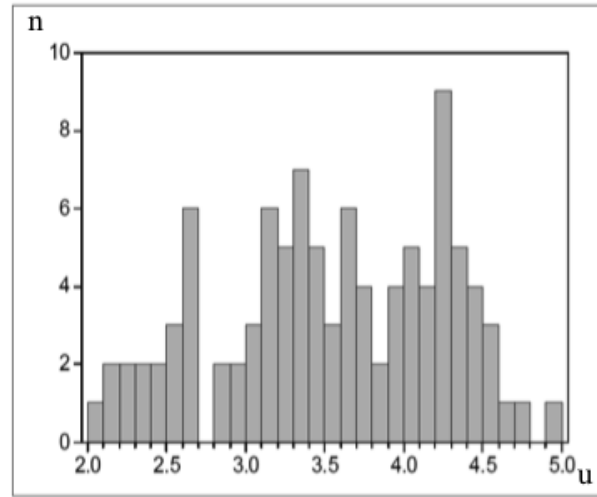

Unemployment-Central Sample Mean:3.50

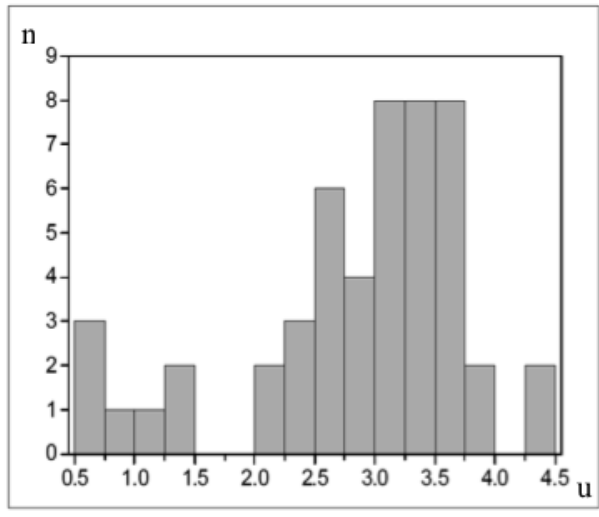

Unemployment-East Sample Mean:2.85

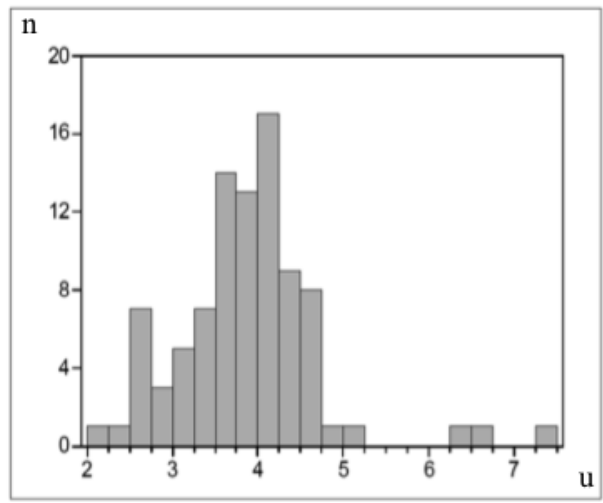

Unemployment-West Sample Mean:3.85

Source: Author's calculation, based on database of National Bureau of Statistics of the People's Republic of China.

Note: $n$ is the number of observations; $u$ is the unemployment rate (\%). 